\title{
Dendritic Nanostructured Waste Copper Wires for High-Energy Alkaline Battery
}

Cite as

Nano-Micro Lett.

(2020) 12:1

Received: 1 October 2019

Accepted: 11 November 2019

Published online: 12 December 2019

(C) The Author(s) 2019

\author{
Nilesh R. Chodankar ${ }^{1,2}$, Su-Hyeon Ji ${ }^{1}$, Young-Kyu Han ${ }^{2}$, Do-Heyoung Kim ${ }^{1} \bowtie$ \\ $\triangle$ Do-Heyoung Kim, kdhh@chonnam.ac.kr \\ 1 School of Chemical Engineering, Chonnam National University, Gwangju 500-757, South Korea \\ 2 Department of Energy and Materials Engineering, Dongguk University, Seoul 100-715, Republic of Korea
}

\section{HIGHLIGHTS}

- Electronic waste $\mathrm{Cu}$ wires were successfully used as a cost-effective current collector for high-energy wire-type rechargeable alkaline batteries.

- The scalable approach was applied to reduce, reuse, and recycle electronic waste.

- A developed wire-type rechargeable alkaline battery exhibited a high-energy-density of $82.42 \mathrm{Wh} \mathrm{kg}^{-1}$ with long-term cycling stability.

\begin{abstract}
Rechargeable alkaline batteries (RABs) have received remarkable attention in the past decade for their high energy, low cost, safe operation, facile manufacture, and ecofriendly nature. To date, expensive electrode materials and current collectors were predominantly applied for RABs, which have limited their real-world efficacy. In the present work, we pro-
\end{abstract}
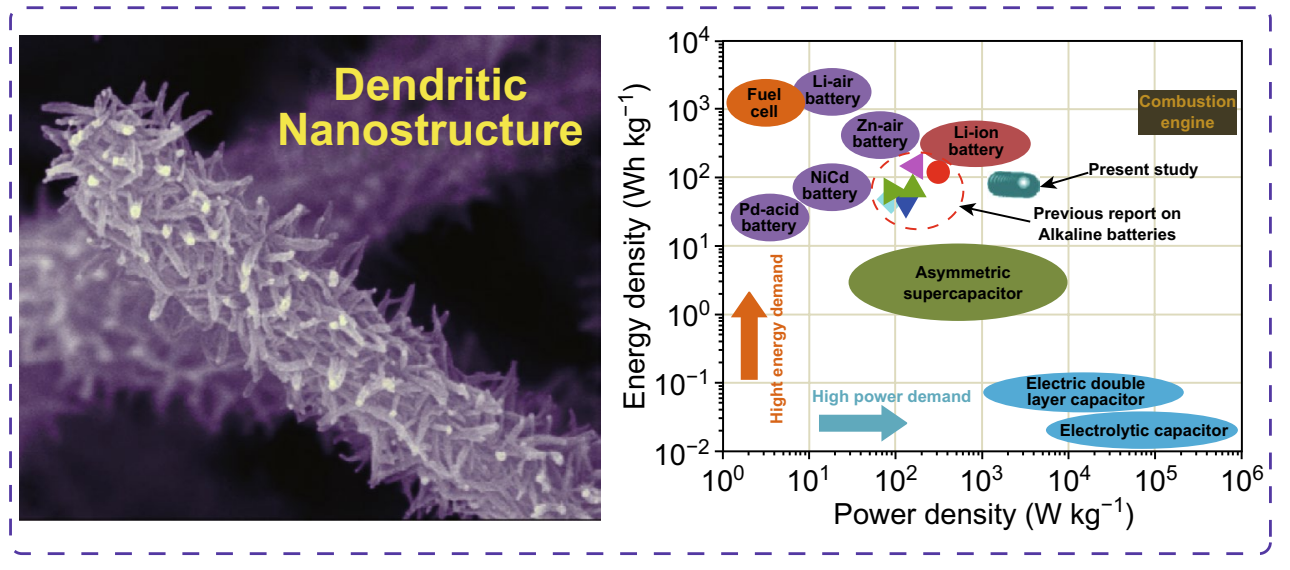
pose a scalable process to utilize electronic waste (e-waste) $\mathrm{Cu}$ wires as a cost-effective current collector for high-energy wire-type RABs. Initially, the vertically aligned $\mathrm{CuO}$ nanowires were prepared over the waste $\mathrm{Cu}$ wires via in situ alkaline corrosion. Then, both atomiclayer-deposited $\mathrm{NiO}$ and $\mathrm{NiCo}$-hydroxide were applied to the $\mathrm{CuO}$ nanowires to form a uniform dendritic-structured NiCo-hydroxide/ $\mathrm{NiO} / \mathrm{CuO} / \mathrm{Cu}$ electrode. When the prepared dendritic-structured electrode was applied to the RAB, it showed excellent electrochemical features, namely high-energy-density ( $\left.82.42 \mathrm{Wh} \mathrm{kg}^{-1}\right)$, excellent specific capacity ( $\left.219 \mathrm{mAh} \mathrm{g}^{-1}\right)$, and long-term cycling stability (94\% capacity retention over 5000 cycles). The presented approach and material meet the requirements of a cost-effective, abundant, and highly efficient electrode for advanced eco-friendly RABs. More importantly, the present method provides an efficient path to recycle e-waste for value-added energy storage applications.

KEYWORDS Alkaline batteries; Dendritic nanostructure; NiCo-hydroxide; Waste Cu wires 


\section{Introduction}

The extensive growth of portable electronics, implantable biomedical devices, and hybrid electrical vehicles demands low-cost, high-performance energy storage devices [1]. In the last two decades, lithium-ion batteries (LIBs) and supercapacitors (SCs) have been the dominant energy storage devices for portable and grid-level applications [2-5]. The higher energy density of LIBs makes them suitable for commercial application; however, the lower power capability, limited cycling stability, high cost, flammability, and toxicity of LIBs have limited their practical utility. In contrast, SCs have attracted immense interest for their higher power capability, long cycle life, and nontoxic nature. However, the surface charge storage mechanism of SCs leads to lower energy density and capacitance values [6]. For certain applications, energy storage devices must exhibit energy densities similar to those of LIBs and power capabilities similar to those of SCs. Recently, rechargeable alkaline batteries (RABs) have been considered as alternative energy storage devices for LIBs and SCs as they show higher energy density than SCs and higher power density than LIBs [7, 8]. Unlike the conventional liquid electrolyte-based planar RABs, wire-type solid-state RABs have recently attracted increased research interest owing to their flexible and lightweight nature, which is suitable for wearable electronics [9-11]. In addition to their flexible and lightweight nature, the lower energy storage capacity due to the smaller operating voltage window and limited cycling stability of wire-type RABs have inspired us to investigate advanced electrode materials, current collectors, and electrolytes to achieve higher energy density and cycling stability. In the literature, various electrode materials were reported to enable RABs to attain higher electrochemical performance. In particular, multicomponent electrode materials in the core-shell form are preferred to obtain higher energy storage capacities due to their synergistic effect $[12,13]$. Nickel cobalt-based nanostructured electrode materials have attracted interest for their high abundance, high capacity, and good reversibility over several electrochemical cycles. In addition, the higher electrical conductivity and redox activity of nickel cobalt-based electrode materials make them suitable candidates for energy storage applications $[14,15]$. Apart from electrode materials, identifying a low-cost current collector is also essential to minimize the production cost of energy storage devices.

The rapidly increasing human population, growing economy, rapid urbanization, and increase in living standards have greatly accelerated the rate of waste generation, thereby directly affecting the earth's atmosphere. Most of this waste is toxic and contains hazardous and health-threatening chemicals. Proper waste management is the best way to maintain a clean atmosphere by reducing, reusing, and recycling our waste $[16,17]$. Among the different types of waste, electronic waste (e-waste) is of serious concern to society and arises from discarding electronic equipment after the end of its useful life. The rapid increase in the demand for advanced electronic devices has led to the constant generation of enormous amounts of e-waste, thereby causing environmental issues, as they contain harmful materials such as lead, cadmium, and beryllium. Electric wires are a universally occurring form of e-waste and primarily contain metallic $\mathrm{Cu}$ or $\mathrm{Al}$. Recycling these metallic waste wires for different energy applications will effectively mitigate economic and environmental concerns [18-22]. To develop an efficient energy storage device that is also cost-effective, it is imperative to search for a common material that could be employed as a current collector, active material, and electrolyte for suitable expanse, as well as possesses adequate energy storage capacity [23, 24]. In general, various current collectors have been used to develop energy storage devices, including stainless steel, carbon cloth, Ti foil, and Ni foam [23]. However, these current collectors are expensive, which will increase the production cost of the energy storage device. To control the production cost, the utilization of waste $\mathrm{Cu}$ wires as a current collector to assemble energy storage devices is the best option.

With this motivation, in the present work, we have developed a wire-type $\mathrm{RAB}$ using waste $\mathrm{Cu}$ wires as a current collector. Briefly, a dendritic-structured NiCo-hydroxide $/ \mathrm{NiO} / \mathrm{CuO} / \mathrm{Cu}$ electrode has been designed by combining wet (alkaline corrosion and chemical bath deposition) and dry (atomic-layer deposition) processes, to yield a high-specific-capacity electrode for batteries, excellent rate capability, and long-term cycling performance when used in an RAB. The designed electrode provides sufficient interspace, as well as a multichannel pathway, for the electrolyte penetration to enable efficient charge and mass transfer within the bulk materials. Moreover, the dendritic-structured electrode prepared over the waste $\mathrm{Cu}$ 
wire itself acts as a self-supportive electrode to control the resultant resistance of the electrode. This synthesis route also provides the facial route to utilize the cost-effective current collector for energy storage applications [25, 26].

\section{Experimental Section}

\subsection{Materials and Chemicals}

All chemicals were used as received from Sigma-Aldrich Corp., South Korea. The copper $(\mathrm{Cu})$ wires used in the experiments were collected from our department's storeroom. All chemicals were analytical grade and used as received without any further processing. All precursor solutions were prepared in deionized water.

\subsection{Preparation of $\mathrm{Cu}(\mathrm{OH})_{2}$ Nanowires on $\mathrm{Cu}$ Wire}

Prior to the preparation of $\mathrm{Cu}(\mathrm{OH})_{2}$ nanowires on the $\mathrm{Cu}$ wire, the plastic coating of the scrap $\mathrm{Cu}$ wire was removed by a wire stripper, and then the obtained $\mathrm{Cu}$ fibers were braided to form a single structure. Furthermore, the $\mathrm{Cu}$ wire was cleaned with $1 \mathrm{M} \mathrm{HCl}$ and deionized (DI) water to remove the native oxide layer from its surface. To grow the $\mathrm{Cu}(\mathrm{OH})_{2}$ nanowires, the typical alkaline corrosion method was used. The precursor solution was prepared by dissolving $\left(\mathrm{NH}_{4}\right)_{2} \mathrm{~S}_{2} \mathrm{O}_{8}(4.107 \mathrm{~g})$ and $\mathrm{NaOH}(11.997 \mathrm{~g})$ in $100 \mathrm{~mL}$ of DI water with continuous stirring for $30 \mathrm{~min}$. The cleaned $\mathrm{Cu}$ fibers were then prepared at a length of $5 \mathrm{~cm}$ and kept in the prepared solution for $5 \mathrm{~min}$ to form the $\mathrm{Cu}(\mathrm{OH})_{2}$ nanowires. The active region of the electrode occupied $4 \mathrm{~cm}$ of the wire, and the remaining $1 \mathrm{~cm}$, was used for the electric contacts. During the reaction time, the color of the solution changed from transparent to blue indicating the formation of $\mathrm{Cu}(\mathrm{OH})_{2}$ nanowires over waste $\mathrm{Cu}$ wires. Furthermore, the prepared $\mathrm{Cu}(\mathrm{OH})_{2} / \mathrm{Cu}$ wire sample was rinsed in DI water and kept at $60{ }^{\circ} \mathrm{C}$ overnight.

\subsection{Preparation of Thin $\mathrm{NiO}$ on the $\mathrm{Cu}(\mathrm{OH})_{2} / \mathrm{Cu}$ Wire}

To enhance the electrical conductivity and surface area of the $\mathrm{Cu}(\mathrm{OH})_{2} / \mathrm{Cu}$ wire, thin $\mathrm{NiO}$ was carried out with a homemade atomic-layer deposition (ALD) system. Commercially available $\mathrm{Ni}(\mathrm{EtCp})_{2}$ was used as the precursor with $\mathrm{O}_{2}$ plasma as the oxidant. The temperature of the precursor was maintained at $50^{\circ} \mathrm{C}$ with a line temperature of $60^{\circ} \mathrm{C}$, and the deposition chamber was maintained at $250{ }^{\circ} \mathrm{C}$. Initially, the ALD conditions were optimized by conducting the deposition of $\mathrm{NiO}$ over a silicon substrate. The standard optimized conditions for the NiO ALD process were as follows: precursor pulsing ( $30 \mathrm{sccm}, 1.5 \mathrm{~s}$ ), main purging ( $30 \mathrm{sccm}, 20 \mathrm{~s}$ ), bypass purging ( $250 \mathrm{sccm}, 5 \mathrm{~s}$ ), oxygen plasma ( $5 \mathrm{~s}$ ), and Ar purging (30 s). Under these conditions, the growth rate of the $\mathrm{NiO}$ layer was $0.037 \mathrm{~nm}$ per cycle at $250^{\circ} \mathrm{C}$. After the ALD parameters were optimized, $\mathrm{NiO}$ was deposited over the $\mathrm{Cu}(\mathrm{OH})_{2} / \mathrm{Cu}$ nanowires for 200 cycles.

\subsection{Preparation of $\mathrm{NiCo}-\mathrm{Hydroxide} / \mathrm{NiO} / \mathrm{CuO} / \mathrm{Cu}$ Electrode}

The nanowires of NiCo-hydroxide were prepared on the $\mathrm{NiO} / \mathrm{CuO} / \mathrm{Cu}$ electrode via low-temperature chemical bath deposition. The precursor solution was prepared by dissolving $0.05 \mathrm{M} \mathrm{Co}\left(\mathrm{NO}_{3}\right)_{2} \cdot \mathrm{H}_{2} \mathrm{O}, 0.05 \mathrm{M} \mathrm{Ni}\left(\mathrm{NO}_{3}\right)_{2} \cdot 6 \mathrm{H}_{2} \mathrm{O}$, and $0.25 \mathrm{M}$ urea in $50 \mathrm{~mL}$ DI water. Afterward, the $\mathrm{NiO} / \mathrm{CuO} /$ $\mathrm{Cu}$ electrode was immersed in the precursor solution and kept in the oven at $80^{\circ} \mathrm{C}$ for $2 \mathrm{~h}$ to form the NiCo-hydroxide nanowires over the $\mathrm{NiO} / \mathrm{CuO} / \mathrm{Cu}$ electrode. After the growth process, the sample was removed from the precursor solution, then rinsed with DI water, and dried in the oven at $60{ }^{\circ} \mathrm{C}$ overnight. The mass loading of the material $(\mathrm{NiO}$ and NiCo-hydroxide) over $\mathrm{CuO} / \mathrm{Cu}$ is $0.56 \mathrm{mg}\left(0.14 \mathrm{mg} \mathrm{cm}^{-1}\right)$. The prepared dendritic-type NiCo-hydroxide/ $/ \mathrm{NiO} / \mathrm{Cu}(\mathrm{OH})_{2} /$ $\mathrm{Cu}$ electrode was used to assemble the wire-type rechargeable aqueous battery.

\subsection{Preparation of Gel Electrolyte and Wire-Type Rechargeable Aqueous Battery}

The PVA-KOH gel electrolyte was prepared by mixing $2 \mathrm{M} \mathrm{KOH}$ and $2 \mathrm{~g}$ of PVA in $20 \mathrm{~mL}$ of DI water at $70{ }^{\circ} \mathrm{C}$ for $20 \mathrm{~min}$ while stirring. The formed transparent gel-like solution was used to assemble the wire-type rechargeable aqueous battery by immersing both electrodes $(4 \mathrm{~cm})$, i.e., NiCo-hydroxide/ $\mathrm{NiO} / \mathrm{CuO} / \mathrm{Cu}$ and $\mathrm{AC} / \mathrm{SS}$, in the PVA-KOH gel electrolyte for $20 \mathrm{~min}$ to cover all the active sites of the material with the gel electrolyte, which was then hung in the oven at $60{ }^{\circ} \mathrm{C}$ for $6 \mathrm{~h}$ to remove the water content from the gel electrolyte. After that, both electrodes were held together and again dipped in the gel electrolyte and solidified at $60{ }^{\circ} \mathrm{C}$ for $6 \mathrm{~h}$. Finally, the assembled device was 
covered with parafilm and used for further electrochemical measurements. The mass ratio of the positive to negative electrode was determined by the well-known charge-balance equation $(q+=q-)$ to be $1: 4.5$.

\subsection{Preparation of Activated Carbon/Stainless Steel Electrode}

To assemble the full rechargeable aqueous battery, a negative electrode is required, whereas $\mathrm{NiCo}-$ hydroxide/NiO/ $\mathrm{CuO} / \mathrm{Cu}$ will act as a positive electrode. To prepare the negative electrode, the stainless steel wires were collected from the 200 stainless steel mesh (304 type). The 20 stainless steel wires were braided to form a uniform structure. The traditional activated carbon coating was carried out over the braided stainless steel wires. Typically, a uniform mixture of the activated carbon (80\%), carbon black (10\%), and PVDF (10\%) with a few drops of ethanol was prepared and loaded over the braided stainless steel wires. To enhance the compatibility between the activated carbon and stainless steel wires, the prepared electrode was heated on a hot plate for $1 \mathrm{~h}$ at $200{ }^{\circ} \mathrm{C}$.

\subsection{Electrochemical Measurements}

The electrochemical measurements for the prepared electrode and wire-type rechargeable aqueous battery were carried out by performing cyclic voltammetry (CV), galvanostatic charge-discharge (GCD), and electrochemical impedance spectroscopy (EIS). For the three-electrode measurements, electrochemical measurements were carried out using the NiCo-hydroxide/ $\mathrm{NiO} / \mathrm{CuO} / \mathrm{Cu}$ electrode as a working electrode, platinum plate as a counter electrode, and saturated calomel electrode (SCE) as the reference electrode in $2 \mathrm{M}$ potassium hydroxide $(\mathrm{KOH})$. The two-electrode measurements were performed by fabricating a wire-type rechargeable aqueous battery with PVA-KOH gel electrolytes.

The thickness of the ALD films was measured by ellipsometry (Gaertner Scientific). The surface morphology of the prepared samples was characterized using field-emission scanning electron microscopy (FE-SEM, JEOL JSM-7500F) and high-resolution transmission electron microscopy (HRTEM, JEOL JEM-2100F). The crystal structure and oxidation state of the prepared samples were confirmed by X-ray diffraction (XRD, X'Pert Pro using CuKg radiation) and X-ray photoelectron spectroscopy (XPS, ESCALAB-MKII).

The electrochemical parameters include the specific capacitance $\left(\mathrm{F} \mathrm{g} \mathrm{g}^{-1}\right)$, length capacitance $\left(\mathrm{mF} \mathrm{cm}^{-1}\right)$, and specific capacity $\left(\mathrm{mAh}^{-1}\right.$ ), which were calculated by the following equations:

Specific capacitance: $C s=I \Delta t /(m \Delta V)$

Length capacitance: $C L=I \Delta t /(L \Delta V)$

Specific capacity: $Q=I \Delta t /(3.6 \mathrm{~m})$

here $I(\mathrm{~A})$ is the discharge current, $\Delta t(\mathrm{~s})$ is the discharge time, $m(\mathrm{~g})$ is the mass of the active material, $\Delta V(\mathrm{~V})$ is the potential, and $L(\mathrm{~cm})$ is the length of the electrode/ device.

\section{Results and Discussion}

The stepwise preparation of the dendritic-structured NiCohydroxide/NiO/CuO/Cu electrode is presented in Fig. 1. Waste management is critical to maintain a clean atmosphere for living creatures. With this motivation, and to minimize e-waste, we used e-waste $\mathrm{Cu}$ wires for energy storage applications. The fabrication of the electrode involves three major steps. First, the plastic nonconducting coating of the waste $\mathrm{Cu}$ wires was removed by wire stepper, and the obtained $\mathrm{Cu}$ wires were treated with an alkaline solution for a very short time $(5 \mathrm{~min})$ to form vertically aligned $\mathrm{Cu}(\mathrm{OH})_{2}$ nanowires. However, the lower electrical conductivity of the $\mathrm{Cu}(\mathrm{OH})_{2}$ is a major obstacle for facial electrochemical reactions [27]. Second, to enhance the electrical conductivity of the $\mathrm{Cu}(\mathrm{OH})_{2}$ nanowires, ALD of NiO film (200 cycles) was carried out on the $\mathrm{Cu}(\mathrm{OH})_{2}$ nanowires. Here, ALD NiO plays multiple roles in enhancing the energy storage capacity of the RAB and enhances the electrical conductivity of the electrode to increase the power capability of the RAB. Furthermore, it will contribute to the redox capacity and allow more active sites to host NiCo-hydroxide. As the ALD of $\mathrm{NiO}$ film was carried out at a reaction temperature of $250{ }^{\circ} \mathrm{C}, \mathrm{Cu}(\mathrm{OH})_{2}$ was converted into $\mathrm{CuO}$, which will, again, be beneficial in enhancing the electrochemical features of the RAB. Finally, the NiCo-hydroxide nanowires were prepared over the $\mathrm{NiO} / \mathrm{CuO} / \mathrm{Cu}$ wires by conventional chemical bath deposition (CBD) at a low reaction temperature of 


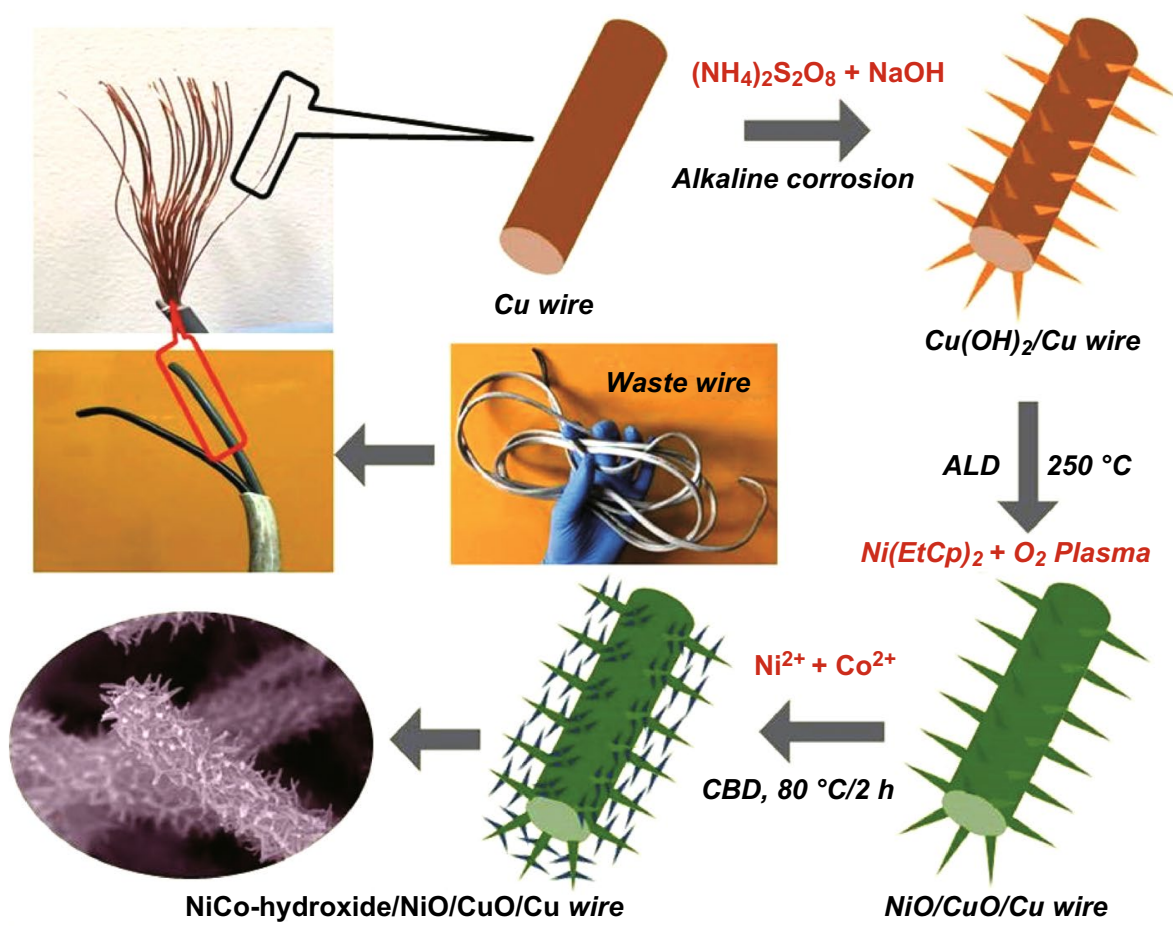

Fig. 1 Schematic illustration of the preparation of dendritic-structured $\mathrm{NiCo}$-hydroxide/ $\mathrm{NiO} / \mathrm{CuO} / \mathrm{Cu}$ electrode using e-waste $\mathrm{Cu}$ wires for the RAB application

$80{ }^{\circ} \mathrm{C}$ to form the dendritic-structured $\mathrm{NiCo}-$ hydroxide/ $\mathrm{NiO} /$ $\mathrm{CuO} / \mathrm{Cu}$ electrode.

The physical and chemical properties of the as-prepared dendritic-structured $\mathrm{NiCo}$-hydroxide/ $\mathrm{NiO} / \mathrm{CuO} / \mathrm{Cu}$ electrode were determined by X-ray diffraction (XRD), X-ray photoelectron spectroscopy (XPS), field-emission scanning electron microscopy (FE-SEM), and transmission electron microscopy (TEM) measurements to verify that the quality of the materials could meet the requirements for RAB applications. Figure 2 shows the FE-SEM and TEM results for the prepared electrodes. As shown in Fig. 2a, b, $\mathrm{Cu}(\mathrm{OH})_{2}$ nanowires are layered uniformly over the $\mathrm{Cu}$ wire after alkaline corrosion. The vertically aligned and well-separated $\mathrm{Cu}(\mathrm{OH})_{2}$ nanowires are beneficial for energy storage applications, as they provide sufficient interspacing for ion movement. However, to overcome the limited conductivity of the $\mathrm{Cu}(\mathrm{OH})_{2}$ nanowires, thin $\mathrm{NiO}$ deposition (200 cycles) is carried out by ALD. Even after 200 ALD NiO cycles, the electrode still maintained basic nanowire-like nanostructures due to the conformal deposition in the ALD technique, as well as maintained its macroscopic nature without blocking the macropores, as shown in Fig. 2c, d [28-30]. TEM analysis for the $\mathrm{NiO} / \mathrm{CuO} / \mathrm{Cu}$ electrode is presented in Fig. S1, which clearly shows the formation of a very thin $(\sim 7 \mathrm{~nm}) \mathrm{NiO}$ coating over the $\mathrm{CuO} / \mathrm{Cu}$ nanowire electrode. The surface morphology of the NiCo-hydroxide/ $\mathrm{NiO} / \mathrm{CuO} /$ $\mathrm{Cu}$ electrode is presented in Fig. 2e-g at different magnifications. The low-magnification images clearly show the formation of the dendritic nanostructures through the surface of the sample (Fig. 2e, f), whereas the high-magnification SEM image shows the formation of very fine and vertically aligned $\mathrm{NiCo}$-hydroxide nanowires over $\mathrm{NiO} / \mathrm{CuO} / \mathrm{Cu}$ to form dendritic nanostructures. TEM images also show the formation of dendritic nanostructures for the NiCo-hydroxide/NiO/CuO/Cu electrode (Fig. 2h, i). After CBD of the NiCo-hydroxide, each $\mathrm{NiO} / \mathrm{CuO} / \mathrm{Cu}$ nanowire is decorated with NiCo-hydroxide nanowires to form a branched nanostructure, which will enhance the energy storage capacity of the RAB by providing a large surface area as well as redox capacity [31, 32]. From the energy storage perspective, this type of nanostructure is favorable for charge storage as it provides a large surface area as well as multiple channels 

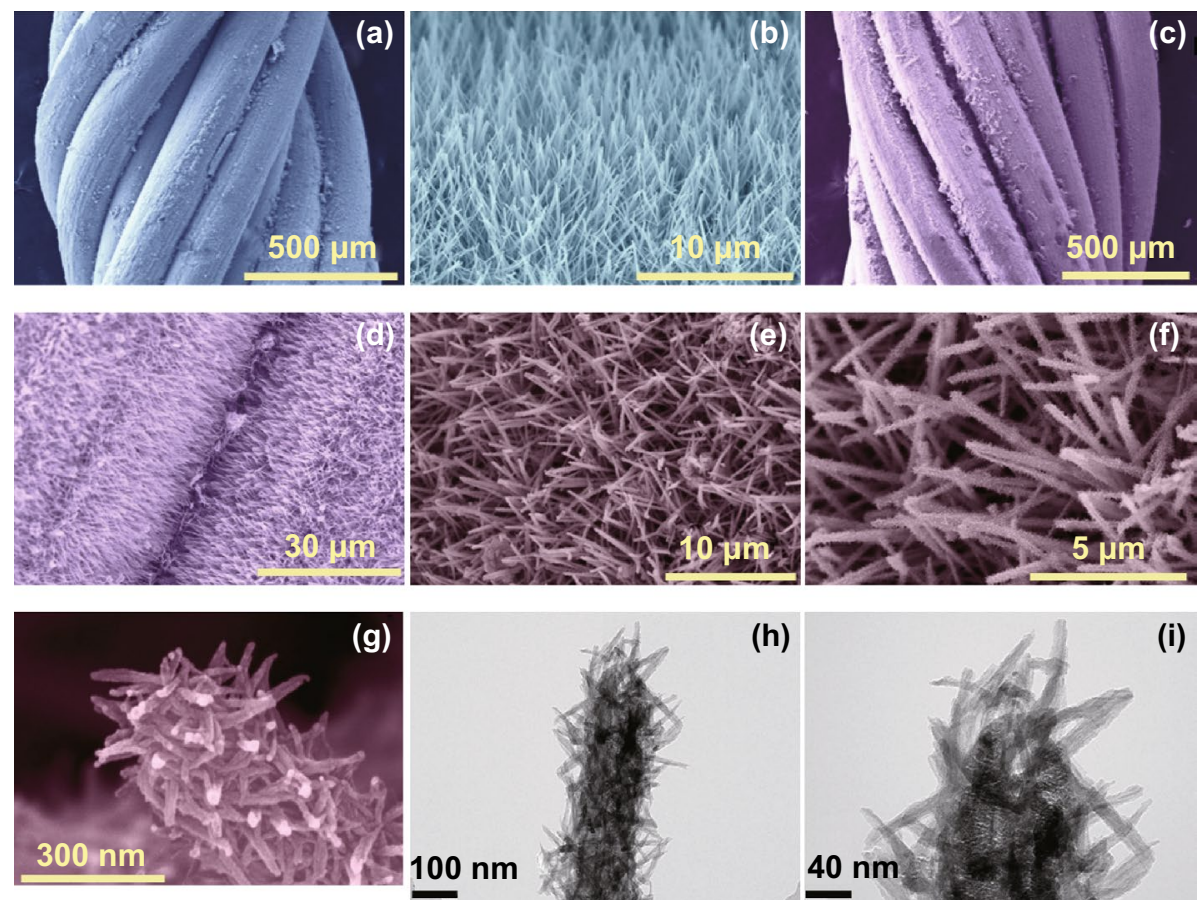

(h)
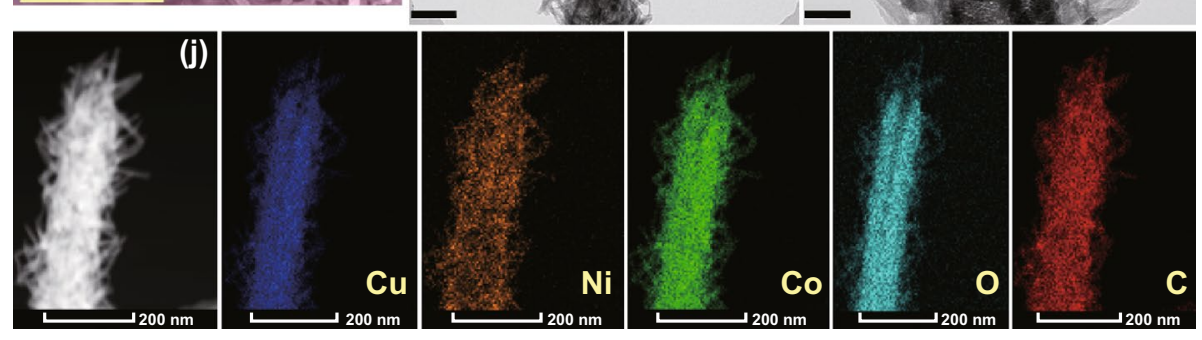

Fig. 2 FE-SEM images for the $\mathbf{a}, \mathbf{b} \mathrm{Cu}(\mathrm{OH})_{2} / \mathrm{Cu}$ wire, $\mathbf{c}, \mathbf{d} \mathrm{NiO} / \mathrm{CuO} / \mathrm{Cu}$, and e-g NiCo-hydroxide/NiO/CuO/Cu electrodes. h, i TEM images for the $\mathrm{NiCo}$-hydroxide/NiO/CuO/Cu electrode. j STEM-EDS elemental mapping results for the NiCo-hydroxide/NiO/CuO/Cu electrode

for charge transfer that will simultaneously boost the energy and power densities. Moreover, each dendritic nanowire is separated from the others by the formation of a porous nanostructure, which will provide large and open channels for the diffusion of electrolyte ions. Scanning transmission electron microscopy (STEM)-energy-dispersive X-ray (EDX) elemental mapping for the $\mathrm{NiCo}-$ hydroxide/ $\mathrm{NiO} / \mathrm{CuO} / \mathrm{Cu}$ electrode is shown in Fig. 2j, which confirms the uniform distribution of each element through the surface of the electrode. The phase and surface chemical state of the prepared electrodes were measured by XRD and XPS, and the corresponding results are presented in Figs. S2, S3.

To demonstrate the electrochemical superiority of the NiCo-hydroxide/NiO/CuO/Cu electrode for the $\mathrm{RAB}$, comparative cyclic voltammetry (CV) measurements were carried out in a three-electrode system with $2 \mathrm{M} \mathrm{KOH}$ electrolyte. Figure 3 a shows the comparative $\mathrm{CV}$ curves for all the electrodes at an identical scan rate of $100 \mathrm{mV} \mathrm{s}^{-1}$, indicating a higher integral area with large anodic and cathodic currents for the $\mathrm{NiCo}$-hydroxide/ $\mathrm{NiO} / \mathrm{CuO} / \mathrm{Cu}$ electrode, thus suggesting a higher energy storage capacity [33]. To prove our claim, we calculated the length capacitance for all the electrodes and plotted them in Fig. 3b. The higher length capacitance of the NiCo-hydroxide/ $\mathrm{NiO} / \mathrm{CuO} / \mathrm{Cu}$ electrode $\left(2.19 \mathrm{~F} \mathrm{~cm}^{-1}\right)$ is indicative of its improved electrochemical features compared to the other electrodes. Furthermore, to determine the rate capability of the NiCo-hydroxide/NiO/ $\mathrm{CuO} / \mathrm{Cu}$ electrode, $\mathrm{CV}$ and charge-discharge (CD) measurements were carried out at various scanning rates, and the corresponding results are presented in Fig. 3c, d. The CV curves show nonrectangular behavior, with a pair of redox peaks indicating the faradaic redox processes of the electrode components. More importantly, the CV curves maintain their shape at both lower and higher scanning rates, 

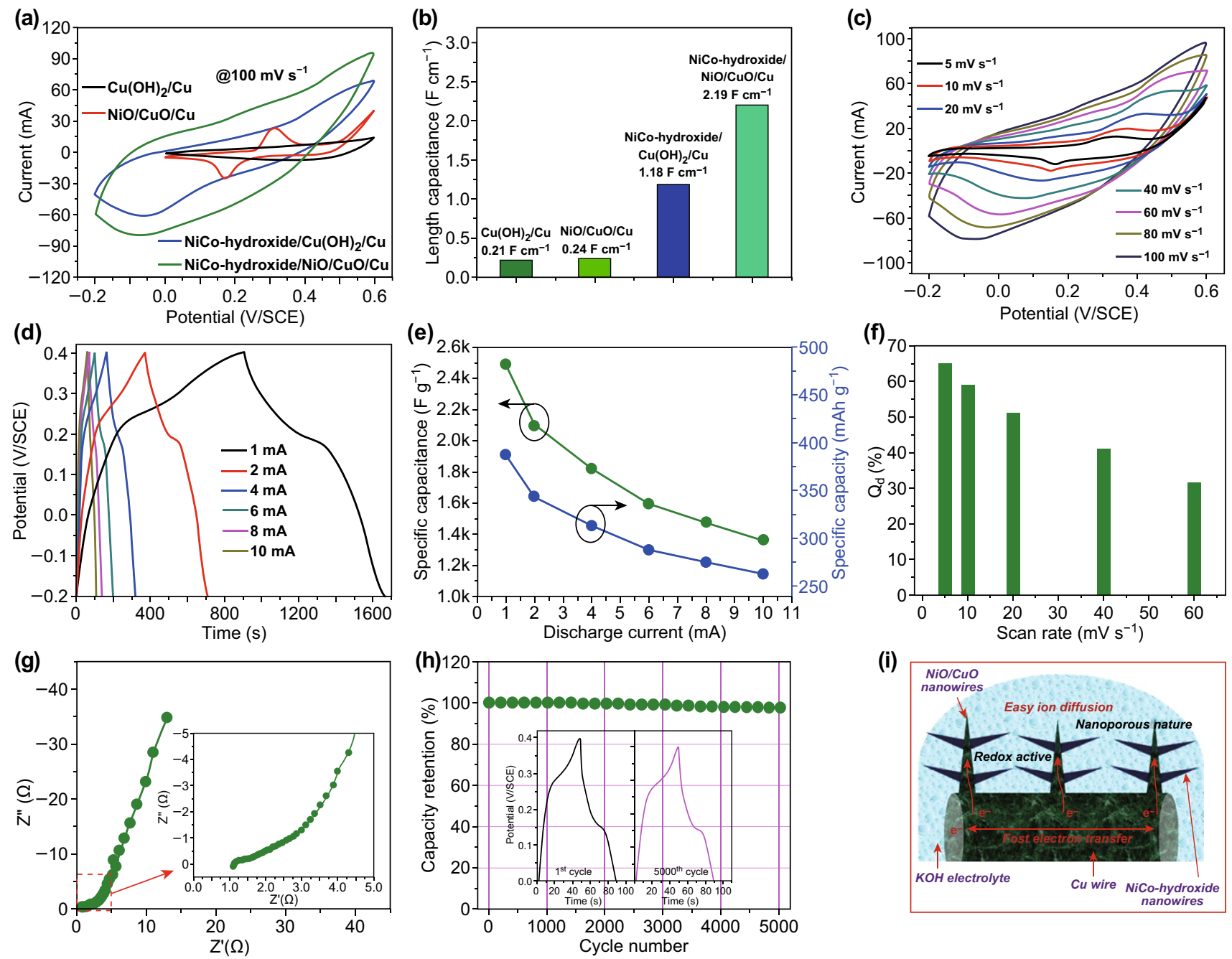

Fig. 3 a Comparative $\mathrm{CV}$ curves and $\mathbf{b}$ corresponding length capacitance for the $\mathrm{Cu}(\mathrm{OH})_{2} / \mathrm{Cu}, \mathrm{NiO} / \mathrm{CuO} / \mathrm{Cu}, \mathrm{NiCo}-\mathrm{hydroxide} / \mathrm{Cu}(\mathrm{OH})_{2} / \mathrm{Cu}$ and NiCo-hydroxide/ $\mathrm{NiO} / \mathrm{CuO} / \mathrm{Cu}$ electrodes at a constant scan rate of $100 \mathrm{mV} \mathrm{s}^{-1}$. c CV and $\mathbf{d} \mathrm{CD}$ curves for the $\mathrm{NiCo}-\mathrm{hydroxide} / \mathrm{NiO} / \mathrm{CuO} / \mathrm{Cu}$ electrode at various scanning rates in $2 \mathrm{M} \mathrm{KOH}$ electrolyte. e specific capacitance and specific capacity for the $\mathrm{NiCo}-\mathrm{hydroxide} / \mathrm{NiO} / \mathrm{CuO} / \mathrm{Cu}$ electrode at various currents. f Plot of diffusion-controlled contribution at different scan rates for the NiCo-hydroxide/ $/ \mathrm{NiO} / \mathrm{CuO} / \mathrm{Cu}$ electrode. $\mathbf{g}$ Nyquist plot for the $\mathrm{NiCo}$-hydroxide/ $\mathrm{NiO} / \mathrm{CuO} / \mathrm{Cu}$ electrode. The inset shows the magnified view of the Nyquist plot. $\mathbf{h}$ Plot of capacity retention versus cycle number for the $\mathrm{NiCo}$-hydroxide/ $\mathrm{NiO} / \mathrm{CuO} / \mathrm{Cu}$ electrode. The inset shows the first and last cycles. i Schematic representation showing the merits of the $\mathrm{NiCo}$-hydroxide/ $\mathrm{NiO} / \mathrm{CuO} / \mathrm{Cu}$ electrode for the $\mathrm{RAB}$ application

signifying better rate capability $[34,35]$. Figure $3 \mathrm{~d}$ shows the representative $\mathrm{CD}$ curves for the $\mathrm{NiCo}$-hydroxide/NiO/ $\mathrm{CuO} / \mathrm{Cu}$ electrode at different currents ranging from 1 to $10 \mathrm{~mA}$. The CD curves show nonlinear behavior, suggesting the existence of faradaic processes, and are consistent with the CV results. The CD curves are approximately symmetric in nature, without any potential drop, even at a higher current of $10 \mathrm{~mA}$, indicating that the dendritic NiCohydroxide/ $\mathrm{NiO} / \mathrm{CuO} / \mathrm{Cu}$ electrode has good electrochemical characteristics and superior reversible redox properties. The discharge-specific capacitance and specific capacity were calculated for the $\mathrm{NiCo}-$ hydroxide/ $\mathrm{NiO} / \mathrm{CuO} / \mathrm{Cu}$ electrode at various currents and are plotted in Fig. 3d. At a low current of $1 \mathrm{~mA}$, the electrode shows the highest specific capacity of $387.37 \mathrm{mAh} \mathrm{g}^{-1}\left(2486 \mathrm{~F} \mathrm{~g}^{-1}\right)$, which decreases to $262.62 \mathrm{mAh} \mathrm{g}^{-1}\left(1363.63 \mathrm{~F} \mathrm{~g}^{-1}\right)$ at a higher current of $10 \mathrm{~mA}$ with a rate capability of $67.79 \%$. This suggests that the developed electrode has better electrochemical characteristics. Furthermore, we quantified the capacitive $\left(Q_{\mathrm{c}}\right)$ and diffusion $\left(Q_{\mathrm{d}}\right)$ controlled contribution to the overall current response in the $\mathrm{CV}$ curves for the NiCo-hydroxide/NiO/ $\mathrm{CuO} / \mathrm{Cu}$ electrode, and the obtained results are presented 
in Fig. 3f. The diffusion-controlled contribution is dominant at low scan rates, whereas the capacitive contribution is higher at a high scan rate. At a low scan rate of $5 \mathrm{mV} \mathrm{s}^{-1}$, the diffusion-controlled contribution is $\sim 65 \%$, indicating the facial diffusion of the electrolyte ions in the active electrode materials for the faradaic reactions. With an increase in scan rate from 5 to $60 \mathrm{mV} \mathrm{s}^{-1}$, it is reasonable to observe that the diffusion-controlled contribution decreases to 32\%, signifying that surface redox reactions dominate at the high scan rate.

To further understand the electrochemical kinetics of the $\mathrm{NiCo}$-hydroxide/ $\mathrm{NiO} / \mathrm{CuO} / \mathrm{Cu}$ electrode, EIS was carried out in the frequency range of $100 \mathrm{kHz}$ to $10 \mathrm{MHz}$. Figure $3 \mathrm{~g}$ shows the obtained Nyquist plot. In order of decreasing frequency, the first intercept of the Nyquist plot in the high-frequency region shows the equivalent series resistance $\left(R_{\mathrm{s}}\right)$, the diameter of the semicircle in the highfrequency region provides the charge transfer resistance $\left(R_{\mathrm{ct}}\right)$, and the vertical line in the low-frequency region represents the electrolyte ion diffusion in the structure of the electrode materials $[36,37]$. In the present case, the NiCohydroxide/NiO/CuO/Cu electrode shows a lower $R_{\mathrm{s}}(1.07$ $\Omega)$ as well as $R_{\mathrm{ct}}(0.32 \Omega)$, suggesting a facial electrochemical reaction between the electrolyte ions and active electrode materials. The long-term cycling stability is, again, an important factor for energy storage devices. Here, the cycling stability for the $\mathrm{NiCo}$-hydroxide/ $\mathrm{NiO} / \mathrm{CuO} / \mathrm{Cu}$ electrode was measured by performing $\mathrm{CD}$ measurements at a high current of $12 \mathrm{~mA}$ for 5000 cycles, where a $97 \%$ capacity retention is observed. The excellent electrochemical performance in terms of higher specific capacity, rate capability, and long-term cycling stability for the dendritic-structured $\mathrm{NiCo}$-hydroxide/ $\mathrm{NiO} / \mathrm{CuO} / \mathrm{Cu}$ electrode is mainly due to its hierarchical nanoporous structure, as schematically presented in Fig. 3i. First, the vertically aligned $\mathrm{CuO}$ nanowires themselves act as a current collector that will drastically reduce the resultant resistance of the electrode. Second, the vertically aligned $\mathrm{CuO}$ nanowires provide a large interspace for electrolyte penetration, as well as to host the $\mathrm{NiO}$ and $\mathrm{NiCo}$-hydroxide [38, 39]. Third, the ALD NiO over the $\mathrm{CuO}$ nanowires enhances the electrical conductivity, resultant surface area, redox sites for the electrochemical reactions, and $\mathrm{NiCo}$-hydroxide hosting [40]. Fourth, the NiCo-hydroxide nanowires over the $\mathrm{NiO} / \mathrm{CuO} / \mathrm{Cu}$ nanowires drastically enhance the electroactive surface area for the redox reactions to enhance the energy storage capacity of the electrode. The interconnected arrangement of the $\mathrm{NiCo}$-hydroxide and $\mathrm{NiO} / \mathrm{CuO} /$ $\mathrm{Cu}$ nanowires creates abundant pathways for electrolyte penetration. The amorphous nature of $\mathrm{NiCo}-\mathrm{OH}$ is favorable for charge storage because it provides abundant grain boundaries and ion diffusion channels. In addition, the binderless approach avoids unnecessary dead surface area by enhancing the electrical conductivity of the electrode [41-43]. Finally, in addition to the synergetic effect of the dendritic structure, the low cost and abundant availability of the waste $\mathrm{Cu}$ wires with low-cost processing make them strong candidates for energy storage applications.

To demonstrate the actual application of the prepared electrode to batteries, an RAB was assembled with $\mathrm{NiCo}$ hydroxide $/ \mathrm{NiO} / \mathrm{CuO} / \mathrm{Cu}$ as a positive electrode and activated carbon (AC)/stainless steel (SS) as a negative electrode with aqueous PVA-KOH gel electrolyte. Figure 4a shows the $\mathrm{CV}$ curves for the $\mathrm{NiCo}-$ hydroxide/ $\mathrm{NiO} / \mathrm{CuO} /$ $\mathrm{Cu}$ and $\mathrm{AC} / \mathrm{SS}$ electrode in the three-electrode system at a constant scan rate of $20 \mathrm{mV} \mathrm{s}^{-1}$ in $2 \mathrm{M} \mathrm{KOH}$ electrolyte. As observed in the CV curve, the NiCo-hydroxide/ $\mathrm{NiO} / \mathrm{CuO} / \mathrm{Cu}$ electrode can work in the positive potential ( -0.2 to $0.6 \mathrm{~V} / \mathrm{SCE}$ ), whereas the AC/SS electrode shows good electrochemical performance in the negative potential ( -1.0 to $0 \mathrm{~V} / \mathrm{SCE})$; therefore, it is possible to combine these electrodes in a single cell to enhance the energy storage capacity and operating voltage of the RAB. To optimize the voltage window for the assembled $\mathrm{NiCo}$-hydroxide/NiO/ $\mathrm{CuO} / \mathrm{Cu} / / \mathrm{AC} / \mathrm{SS} \mathrm{RAB}$, the $\mathrm{CV}$ measurements were carried out at various voltage windows (Fig. 4b). The optimized voltage limit for the $\mathrm{NiCo}$-hydroxide/ $\mathrm{NiO} / \mathrm{CuO} / \mathrm{Cu} / / \mathrm{AC} /$ $\mathrm{SS} \mathrm{RAB}$ is $1.5 \mathrm{~V}$. However, from the three-electrode measurements, the maximum operating voltage window for the proposed RAB is $1.6 \mathrm{~V}$. To maintain the long-term cycling stability and reversibility of the electrodes, we selected the voltage limit of $0-1.5 \mathrm{~V}[44,45]$. Figure $4 \mathrm{c}$ shows the CV curves for the NiCo-hydroxide/ $/ \mathrm{NiO} / \mathrm{CuO} / \mathrm{Cu} / / \mathrm{AC} / \mathrm{SS} \mathrm{RAB}$ at various scanning rates within the voltage limit of $0-1.5 \mathrm{~V}$. The CV curves maintain their CV shape at both lower and higher scan rates, suggesting better electrochemical features with excellent rate capability. The assembled NiCohydroxide/ $\mathrm{NiO} / \mathrm{CuO} / \mathrm{Cu} / / \mathrm{AC} / \mathrm{SS} \mathrm{RABs}$ work very well, even at a high scan rate of $100 \mathrm{mV} \mathrm{s}^{-1}$ by sustaining the original $\mathrm{CV}$ curve, indicating the higher electrical conductivity of the electrode and electrolyte. Figure $4 \mathrm{~d}$ presents the $\mathrm{CD}$ curves for the NiCo-hydroxide/ $\mathrm{NiO} / \mathrm{CuO} / \mathrm{Cu} / / \mathrm{AC} /$ 

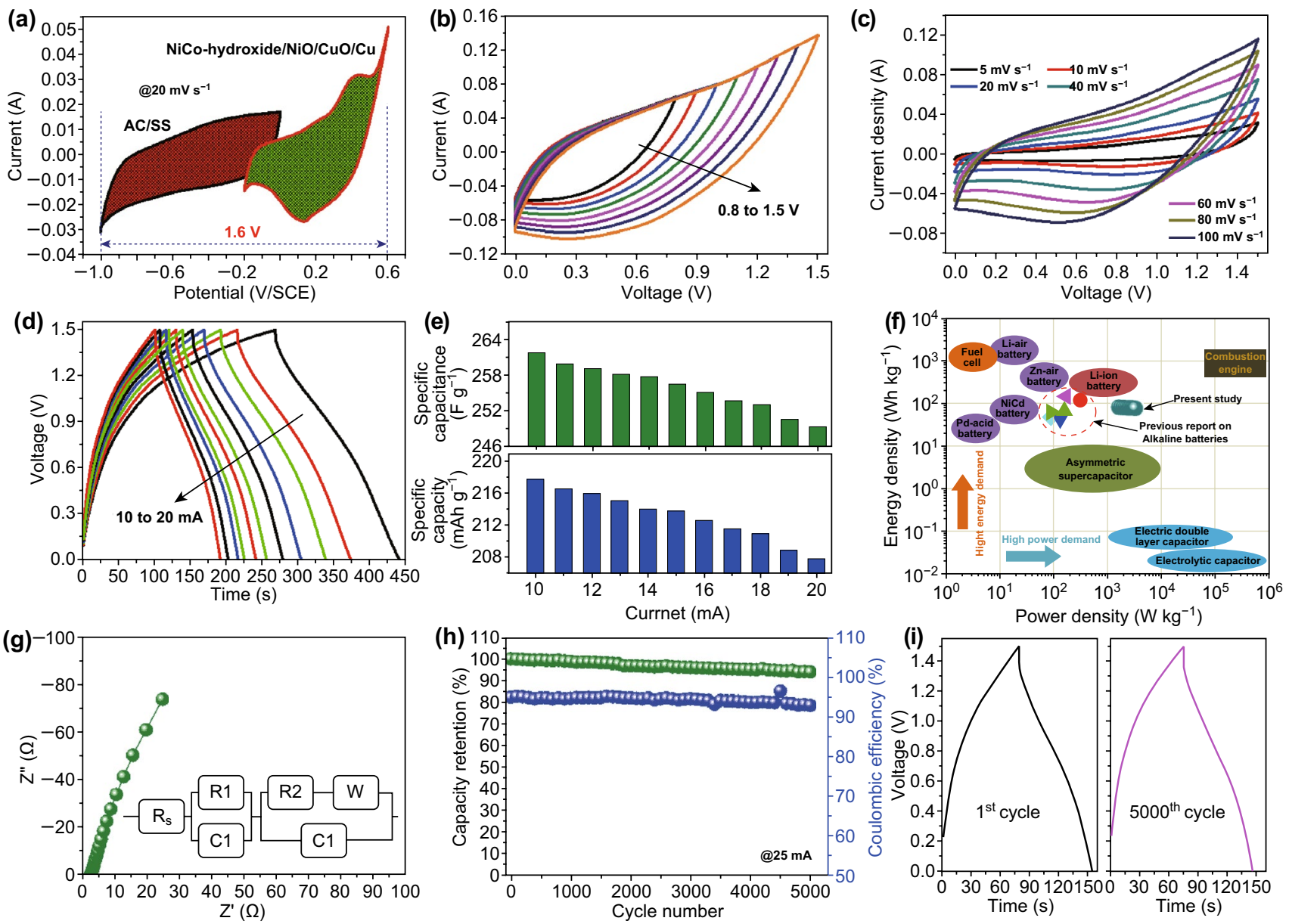

Fig. $4 \mathrm{CV}$ curves for a the AC/SS and NiCo-hydroxide/ $\mathrm{NiO} / \mathrm{CuO} / \mathrm{Cu}$ electrode in $2 \mathrm{KOH}$ electrolyte at a constant scan rate of $20 \mathrm{mV} \mathrm{s}^{-1}$, $\mathbf{b}$ the $\mathrm{NiCo}$-hydroxide/ $\mathrm{NiO} / \mathrm{CuO} / \mathrm{Cu} / / \mathrm{AC} / \mathrm{SS} \mathrm{RAB}$ at various applied voltage ranges, and $\mathrm{c}$ the NiCo-hydroxide/NiO/CuO/Cu//AC/SS RAB at various scan rates in the voltage window of $0-1.5 \mathrm{~V}$. $\mathbf{d}$ CD curves for the NiCo-hydroxide/ $\mathrm{NiO} / \mathrm{CuO} / \mathrm{Cu} / / \mathrm{AC} / \mathrm{SS} \mathrm{RAB}$ at various currents. e Plot of specific capacitance and specific capacity at various discharge current for the NiCo-hydroxide/NiO/CuO/Cu//AC/SS RAB. f Ragone plot for the NiCo-hydroxide/NiO/CuO/Cu//AC/SS RAB. g Nyquist plot for the NiCo-hydroxide/NiO/CuO/Cu//AC/SS RAB; the inset shows the fitted equivalent circuit. $\mathbf{h}$ Plot of capacity retention and coulombic efficiency for the NiCo-hydroxide/NiO/CuO/Cu//AC/SS RAB; and $\mathbf{i}$ initial and final CD cycles at a constant current of $25 \mathrm{~mA}$

SS RAB at various currents within the voltage window of 0-1.5 V. Based on the CD curves, we calculated the specific capacitance and specific capacity for the NiCo-hydroxide/ $\mathrm{NiO} / \mathrm{CuO} / \mathrm{Cu} / / \mathrm{AC} / \mathrm{SS} \mathrm{RAB}$ at various currents, and the corresponding results are presented in Fig. 4d. At the low current of $10 \mathrm{~mA}$, the $\mathrm{NiCo}$-hydroxide $/ \mathrm{NiO} / \mathrm{CuO} / \mathrm{Cu} / / \mathrm{AC} / \mathrm{SS}$ $\mathrm{RAB}$ shows a specific capacity of $219 \mathrm{mAh} \mathrm{g}^{-1}\left(263 \mathrm{~F} \mathrm{~g}^{-1}\right)$, which then decreases to $207 \mathrm{mAh} \mathrm{g}^{-1}\left(249 \mathrm{~F} \mathrm{~g}^{-1}\right)$ at a high current density of $20 \mathrm{~mA}$, corresponding to a rate capability of $94.17 \%$. Furthermore, the energy density and power density were calculated for the $\mathrm{NiCo}$-hydroxide/ $\mathrm{NiO} / \mathrm{CuO} /$ $\mathrm{Cu} / / \mathrm{AC} / \mathrm{SS} \mathrm{RAB}$ by considering the discharge curves, and the corresponding results are plotted in the Ragone plot
(Fig. 4f). The device exhibited the highest energy density of $82.42 \mathrm{Wh} \mathrm{kg}^{-1}$ at a power density of $1630.43 \mathrm{~W} \mathrm{~kg}^{-1}$, and a high power density of $3660.87 \mathrm{~W} \mathrm{~kg}^{-1}$ at an energy density of $77.89 \mathrm{Wh} \mathrm{kg}^{-1}$. Importantly, the assembled NiCohydroxide/NiO/CuO/Cu//AC/SS RAB simultaneously shows higher energy and power densities, thereby expanding the applicability of the battery technology. Further, the obtained energy densities are higher than those for lead acid, vanadium redox flow, and aqueous LIBs and SIBs [46, 47]. EIS was further used to investigate the electrochemical properties of the NiCo-hydroxide/NiO/CuO/Cu//AC/SS RAB. The Nyquist plot (Fig. $4 \mathrm{~g}$ ) shows that $R_{\mathrm{s}}$ and $R_{\mathrm{ct}}$ are less than $3 \Omega$, indicating the occurrence of facial electrochemical reactions 
between the electrode material and electrolyte ions. In addition, long-term cycling stability measurements were carried out for the NiCo-hydroxide/NiO/CuO/Cu//AC/SS RAB, and the corresponding results are presented in Fig. 4h, i. As shown in Fig. 4h, the NiCo-hydroxide/NiO/CuO/Cu//AC/ SS RAB shows excellent cycling stability by maintaining $94 \%$ of capacity over the $5000 \mathrm{CD}$ cycles. Moreover, the NiCo-hydroxide/NiO/CuO/Cu//AC/SS RAB shows a better columbic efficiency of $93 \%$, even after 5000 cycles, representing the excellent reversibility of the electrode materials. Moreover, Fig. 4i shows the initial and final CD cycles with similar electrochemical characteristics, indicating the superior electrochemical performance of the NiCo-hydroxide/ $\mathrm{NiO} / \mathrm{CuO} / \mathrm{Cu} / / \mathrm{AC} / \mathrm{SS} \mathrm{RAB}$. The above-mentioned results indicate that the dendritic-structured NiCo-hydroxide $/ \mathrm{NiO} /$ $\mathrm{CuO} / \mathrm{Cu}$ electrode exhibits excellent electrochemical features that are suitable for high-energy RAB applications.

\section{Conclusions}

In conclusion, a uniform dendritic-structured NiCo-hydroxide/ $\mathrm{NiO} / \mathrm{CuO} / \mathrm{Cu}$ electrode was successfully fabricated over a waste $\mathrm{Cu}$ wire via a low-cost and scalable process for a high-energy RAB. The electrochemical investigation for the developed RAB shows excellent features in terms of a highenergy-density ( $82.42 \mathrm{Wh} \mathrm{kg}^{-1}$ ), excellent specific capacity $\left(219 \mathrm{mAh} \mathrm{g}^{-1}\right)$, and long-term cycling stability $(94 \%$ capacity retention over 5000 cycles). The excellent electrochemical properties result from the innovative design of the hierarchical nanostructure with a highly porous branched nanostructure that provides a multichannel for facial and fast ion transportation during the charge/discharge process. More importantly, the simple synthetic approach provided in this work is highly repeatable and easy to scale up for different applications. Finally, the presented approach and material meet the requirements of cost-effectiveness, abundance, and high effectiveness of the electrode for advanced eco-friendly energy storage devices.

Acknowledgements This research was supported by the National Research Foundation of Korea (NRF- 2017R1E1A1A03070930). We thank the Korea Basic Science Institute (KBSI) at Gwangju Center for the SEM and TEM analysis.

Open Access This article is distributed under the terms of the Creative Commons Attribution 4.0 International License (http:// creativecommons.org/licenses/by/4.0/), which permits unrestricted use, distribution, and reproduction in any medium, provided you give appropriate credit to the original author(s) and the source, provide a link to the Creative Commons license, and indicate if changes were made.

Electronic supplementary material The online version of this article (https://doi.org/10.1007/s40820-019-0337-2) contains supplementary material, which is available to authorized users.

\section{References}

1. J. Leng, Z. Wang, J. Wang, H.H. Wu, G. Yan et al., Advances in nanostructures fabricated via spray pyrolysis and their applications in energy storage and conversion. Chem. Soc. Rev. 48, 3015-3072 (2019). https://doi.org/10.1039/C8CS0 0904J

2. G.G. Yadav, D. Turney, J. Huang, X. Wei, S. Banerjee, Breaking the $2 \mathrm{~V}$ barrier in aqueous Zinc chemistry: Creating 2.45 and $2.8 \mathrm{~V} \mathrm{MnO}_{2}-\mathrm{Zn}$ aqueous batteries. ACS Energy Lett. 4, 2144-2146 (2019). https://doi.org/10.1021/acsenergyl ett.9b01643

3. T.S. Mathis, N. Kurra, X. Wang, D. Pinto, P. Simon, Y. Gogotsi, Energy storage data reporting in perspectiveguidelines for interpreting the performance of electrochemical energy storage systems. Adv. Energy Mater. (2019). https ://doi.org/10.1002/aenm.201902007

4. S. Ghosh, S.M. Jeong, S.R. Polaki, A review on metal nitrides/oxynitrides as an emerging supercapacitor electrode beyond oxide. Korean J. Chem. Eng. 35, 1389-1408 (2018). https://doi.org/10.1007/s11814-018-0089-6

5. P. Zhang, D. Wang, Q. Zhu, N. Sun, F. Fu, B. Xu, Plate-tolayer $\mathrm{Bi}_{2} \mathrm{MoO}_{6} /$ mxene-heterostructured anode for lithiumion batteries. Nano Micro Lett. 11, 81 (2019). https://doi. org/10.1007/s40820-019-0312-y

6. D.P. Dubal, O. Ayyad, V. Ruiz, P. Gómez-Romero, Hybrid energy storage: the merging of battery and supercapacitor chemistries. Chem. Soc. Rev. 44, 1777-1790 (2015). https ://doi.org/10.1039/C4CS00266K

7. H. Qin, Z. Yang, L. Chen, X. Chen, L. Wang, A high-rate aqueous rechargeable zinc ion battery based on the $\mathrm{VS}_{4} @$ rGO nanocomposite. J. Mater. Chem. A 6, 23757-23765 (2018). https://doi.org/10.1039/C8TA08133F

8. W. Li, B. Zhang, R. Lin, S.M. Ho-Kimura, G. He, X. Zhou, J. Hu, I.P. Parkin, A dendritic nickel cobalt sulfide nanostructure for alkaline battery electrodes. Adv. Funct. Mater. 28, 1705937 (2018). https://doi.org/10.1002/adfm.20170 5937

9. Z. Wang, Z. Ruan, Z. Liu, Y. Wang, Z. Tang et al., A flexible rechargeable zinc-ion wire-shaped battery with shape memory function. J. Mater. Chem. A 6, 8549-8557 (2018). https://doi. org/10.1039/C8TA01172A

10. K. Wang, X. Zhang, J. Han, X. Zhang, X. Sun, C. Li, W. Liu, Q. Li, Y. Ma, High-performance cable-type flexible rechargeable $\mathrm{Zn}$ battery based on $\mathrm{MnO}_{2} @ \mathrm{CNT}$ fiber microelectrode. 
ACS Appl. Mater. Interfaces 10, 24573-24582 (2018). https ://doi.org/10.1021/acsami.8b07756

11. G. Fang, J. Zhou, A. Pan, S. Liang, Recent advances in aqueous Zinc-ion batteries. ACS Energy Lett. 3, 2480-2501 (2018). https://doi.org/10.1021/acsenergylett.8b01426

12. S. Zhu, Z. Wang, F. Huang, H. Zhang, S. Li, Hierarchical $\mathrm{Cu}(\mathrm{OH})_{2} @ \mathrm{Ni}_{2}(\mathrm{OH})_{2} \mathrm{CO}_{3}$ core/shell nanowire arrays in situ grown on three-dimensional copper foam for high-performance solid-state supercapacitors. J. Mater. Chem. A 5, 9960-9969 (2017). https://doi.org/10.1039/C7TA01805C

13. G. Nagaraju, S.C. Sekhar, J.S. Yu, Utilizing waste cable wires for high-performance fiber-based hybrid supercapacitors: an effective approach to electronic-waste management. Adv. Energy Mater. 8, 1702201 (2018). https://doi.org/10.1002/ aenm.201702201

14. G. He, X. Han, R. Zou, T. Zhao, Z. Weng et al., A targeted functional design for highly efficient and stable cathodes for rechargeable Li-ion batteries. Adv. Funct. Mater. 27, 1604903 (2017). https://doi.org/10.1002/adfm.201604903

15. G. He, M. Qiao, W. Li, Y. Lu, T. Zhao et al., S, N-Co-Doped graphene-nickel cobalt sulfide aerogel: improved energy storage and electrocatalytic performance. Adv. Sci. 4, 1600214 (2017). https://doi.org/10.1002/advs.201600214

16. D.Y. Chung, Y.J. Son, J.M. Yoo, J.S. Kang, C.Y. Ahn, S. Park, Y.E. Sung, Coffee waste-derived hierarchical porous carbon as a highly active and durable electrocatalyst for electrochemical energy applications. ACS Appl. Mater. Interfaces 9, 41303-41313 (2017). https://doi.org/10.1021/ acsami.7b13799

17. A. Gutierrez, L. Miró, A. Gil, J. Rodríguez-Aseguinolaza, C. Barreneche et al., Industrial waste materials and by-products as thermal energy storage (TES) materials: a review. AIP Conf. Proc. 1734, 050019 (2016). https://doi.org/10.1063/1.4949117

18. R. Cayumil, R. Khanna, R. Rajarao, P.S. Mukherjee, V. Sahajwalla, Concentration of precious metals during their recovery from electronic waste. Waste Manag. 57, 121-130 (2016). https://doi.org/10.1016/j.wasman.2015.12.004

19. R.R. Rajagopal, L.S. Aravinda, R. Rajarao, B.R. Bhat, V. Sahajwalla, Activated carbon derived from non-metallic printed circuit board waste for supercapacitor application. Electrochim. Acta 211, 488-498 (2016). https://doi. org/10.1016/j.electacta.2016.06.077

20. A. Shokri, F. Pahlevani, K. Levick, I. Cole, V. Sahajwalla, Synthesis of copper-tin nanoparticles from old computer printed circuit boards. J. Clean. Prod. 142, 2586-2592 (2017). https://doi.org/10.1016/j.jclepro.2016.11.017

21. R. Rajarao, V. Sahajwalla, R. Cayumil, M. Park, R. Khanna, Novel approach for processing hazardous electronic waste. Procedia Environ. Sci. 21, 33-41 (2014). https://doi. org/10.1016/j.proenv.2014.09.005

22. J. Cui, E. Forssberg, Mechanical recycling of waste electric and electronic equipment: a review. J. Hazard. Mater. 99, 243263 (2003). https://doi.org/10.1016/S0304-3894(03)00061-X

23. D.P. Dubal, N.R. Chodankar, D.H. Kim, P. Gomez-Romero, Towards flexible solid-state supercapacitors for smart and wearable electronics. Chem. Soc. Rev. 47, 2065-2129 (2018). https://doi.org/10.1039/C7CS00505A

24. N.R. Chodankar, S. Selvaraj, S.H. Ji, Y. Kwon, D.H. Kim, Interface-engineered nickel cobaltite nanowires through nio atomic layer deposition and nitrogen plasma for high-energy, long-cycle-life foldable all-solid-state supercapacitors. Small 15, 1803716 (2019). https://doi.org/10.1002/smll.201803716

25. Q. Hu, J.Y. Liao, X.D. He, S. Wang, L.N. Xiao, X. Ding, C.H. Chen, In situ catalytic formation of graphene-like graphitic layer decoration on $\mathrm{Na}_{3} \mathrm{~V}_{2}-\mathrm{xGax}\left(\mathrm{PO}_{4}\right)_{3}$ for ultrafast and high energy sodium storage. J. Mater. Chem. A 7, 4660-4667 (2019). https://doi.org/10.1039/C8TA11890F

26. S. Choi, D.H. Seo, M.R. Kaiser, C. Zhang, T. Van Der Laan et al., $\mathrm{WO}_{3}$ nanolayer coated 3D-graphene/sulfur composites for high performance lithium/sulfur batteries. J. Mater. Chem. A 7, 4596-4603 (2019). https://doi.org/10.1039/C8TA11646F

27. Z. Yu, J. Thomas, Energy storing electrical cables: integrating energy storage and electrical conduction. Adv. Mater. 26, 4279-4285 (2014). https://doi.org/10.1002/adma.201400440

28. S.H. Ji, W.S. Jang, J.W. Son, D.H. Kim, Characteristics of $\mathrm{NiO}$ films prepared by atomic layer deposition using bis(ethylcyclopentadienyl)-Ni and $\mathrm{O}_{2}$ plasma. Korean $\mathrm{J}$. Chem. Eng. 35, 2474-2479 (2018). https://doi.org/10.1007/ s11814-018-0179-5

29. M. Zafar, J.Y. Yun, D.H. Kim, Highly stable inverted organic photovoltaic cells with a $\mathrm{V}_{2} \mathrm{O}_{5}$ hole transport layer. Korean J. Chem. Eng. 34, 1504-1508 (2017). https://doi.org/10.1007/ s11814-017-0043-z

30. C. Guan, J. Wang, Recent development of advanced electrode materials by atomic layer deposition for electrochemical energy storage. Adv. Sci. 3, 1500405 (2016). https://doi. org/10.1002/advs.201500405

31. T. Wang, S. Zhang, X. Yan, M. Lyu, L. Wang, J. Bell, H. Wang, 2-Methylimidazole-derived $\mathrm{Ni}$ - Co layered double hydroxide nanosheets as high rate capability and high energy density storage material in hybrid supercapacitors. ACS Appl. Mater. Interfaces 9, 15510-15524 (2017). https://doi. org/10.1021/acsami.7b02987

32. H. Chen, L. Hu, M. Chen, Y. Yan, L. Wu, Nickel-Cobalt layered double hydroxide nanosheets for high-performance supercapacitor electrode materials. Adv. Funct. Mater. 24, 934-942 (2014). https://doi.org/10.1002/adfm.201301747

33. S. Ghosh, W.D. Yong, E.M. Jin, S.R. Polaki, S.M. Jeong, H. Jun, Mesoporous carbon nanofiber engineered for improved supercapacitor performance. Korean J. Chem. Eng. 36, 312 320 (2019). https://doi.org/10.1007/s11814-018-0199-1

34. N.R. Chodankar, D.P. Dubal, S.H. Ji, D.H. Kim, Superfast electrodeposition of newly developed $\mathrm{RuCo}_{2} \mathrm{O}_{4}$ nanobelts over low-cost stainless steel mesh for high-performance aqueous supercapacitor. Adv. Mater. Interfaces 5, 1800283 (2018). https://doi.org/10.1002/admi.201800283

35. D. Yan, W. Wang, X. Luo, C. Chen, Y. Zeng, Z. Zhu, $\mathrm{NiCo}_{2} \mathrm{O}_{4}$ with oxygen vacancies as better performance electrode material for supercapacitor. Chem. Eng. J. 334, 864-872 (2018). https://doi.org/10.1016/j.cej.2017.10.128 
36. D.P. Dubal, N.R. Chodankar, R. Holze, D.-H. Kim, P. GomezRomero, Ultrathin Mesoporous $\mathrm{RuCo}_{2} \mathrm{O}_{4}$ nanoflakes: an advanced electrode for high-performance asymmetric supercapacitors. ChemSusChem 10, 1771-1782 (2017). https://doi. org/10.1002/cssc. 201700001

37. P. Huang, D. Pech, R. Lin, J.K. McDonough, M. Brunet et al., On-chip micro-supercapacitors for operation in a wide temperature range. Electrochem. Commun. 36, 53-56 (2013). https://doi.org/10.1016/j.elecom.2013.09.003

38. Y. Wang, J. Zeng, J. Li, X. Cui, A.M. Al-Enizi, L. Zhang, G. Zheng, One-dimensional nanostructures for flexible supercapacitors. J. Mater. Chem. A 3, 16382-16392 (2015). https:// doi.org/10.1039/C5TA03467A

39. Y. Xia, P. Yang, Y. sun, Y. Wu, B. Mayers et al., Onedimensional nanostructures: synthesis, characterization, and applications. Adv. Mater. 15, 353-389 (2003). https://doi. org/10.1002/adma.200390087

40. R. Warren, F. Sammoura, F. Tounsi, M. Sanghadasa, L. Lin, Highly active ruthenium oxide coating via ALD and electrochemical activation in supercapacitor applications. J. Mater. Chem. A 3, 15568-15575 (2015). https://doi.org/10.1039/ C5TA03742E

41. C. Yuan, J. Li, L. Hou, X. Zhang, L. Shen, X.W. Lou, Ultrathin mesoporous $\mathrm{NiCo}_{2} \mathrm{O}_{4}$ nanosheets supported on $\mathrm{Ni}$ foam as advanced electrodes for supercapacitors. Adv. Funct. Mater. 22, 4592-4597 (2012). https://doi.org/10.1002/adfm.20120 0994

42. L. Liu, H. Zhao, Y. Wang, Y. Fang, J. Xie, Y. Lei, Evaluating the role of nanostructured current collectors in energy storage capability of supercapacitor electrodes with thick electroactive materials layers. Adv. Funct. Mater. 28, 1705107 (2018). https ://doi.org/10.1002/adfm.201705107

43. X. Li, H. Wu, A.M. Elshahawy, L. Wang, S.J. Pennycook, C. Guan, J. Wang, Cactus-like NiCoP/NiCo-OH 3D architecture with tunable composition for high-performance electrochemical capacitors. Adv. Funct. Mater. 28(20), 11800036 (2018). https://doi.org/10.1002/adfm.201800036

44. Q. Jiang, N. Kurra, M. Alhabeb, Y. Gogotsi, H.N. Alshareef, All pseudocapacitive $\mathrm{MXene}-\mathrm{RuO}_{2}$ asymmetric supercapacitors. Adv. Energy Mater. 8, 1703043 (2018). https://doi. org/10.1002/aenm.201703043
45. Z. Dai, C. Peng, J.H. Chae, K.C. Ng, G.Z. Chen, Cell voltage versus electrode potential range in aqueous supercapacitors. Sci. Rep. 5, 9854 (2015). https://doi.org/10.1038/srep09854

46. Y. Wang, J. Yi, Y. Xia, Recent progress in aqueous lithium-ion batteries. Adv. Energy Mater. 2, 830-840 (2012). https://doi. org/10.1002/aenm.201200065

47. W. Tang, L. Liu, Y. Zhu, H. Sun, Y. Wu, K. Zhu, An aqueous rechargeable lithium battery of excellent rate capability based on a nanocomposite of $\mathrm{MoO}_{3}$ coated with PPy and $\mathrm{LiMn}_{2} \mathrm{O}_{4}$. Energy Environ. Sci. 5, 6909-6913 (2012). https:// doi.org/10.1039/c2ee21294c

48. Z. Zhu, R. Zhang, J. Lin, K. Zhang, N. Li, C. Zhao, G. Chen, C. Zhao, $\mathrm{Ni}, \mathrm{Zn}$-codoped $\mathrm{MgCo}_{2} \mathrm{O}_{4}$ electrodes for aqueous asymmetric supercapacitor and rechargeable $\mathrm{Zn}$ battery. J. Power Sour. 437, 226941 (2019). https://doi.org/10.1016/j. jpowsour.2019.226941

49. X. Wu, M. Sun, S. Guo, J. Qian, Y. Liu, Y. Cao, X. Ai, H. Yang, Vacancy-free prussian blue nanocrystals with high capacity and superior cyclability for aqueous sodium-ion batteries. ChemNanoMat 1, 188-193 (2015). https://doi. org/10.1002/cnma.201500021

50. X. Wu, Y. Cao, X. Ai, J. Qian, H. Yang, A low-cost and environmentally benign aqueous rechargeable sodium-ion battery based on $\mathrm{NaTi}_{2}\left(\mathrm{PO}_{4}\right)_{3}-\mathrm{Na}_{2} \mathrm{NiFe}(\mathrm{CN})_{6}$ intercalation chemistry. Electrochem. Commun. 31, 145-148 (2013). https://doi. org/10.1016/j.elecom.2013.03.013

51. X.Y. Wu, M.Y. Sun, Y.F. Shen, J.F. Qian, Y.L. Cao, X.P. Ai, H.X. Yang, Energetic aqueous rechargeable Sodium-Ion battery based on $\mathrm{Na}_{2} \mathrm{CuFe}(\mathrm{CN})_{6}-\mathrm{NaTi}_{2}\left(\mathrm{PO}_{4}\right)_{3}$ intercalation chemistry. ChemSusChem 7, 407-411 (2014). https://doi. org/10.1002/cssc.201301036

52. K. Lu, B. Song, Y. Zhang, H. Ma, J. Zhang, Encapsulation of zinc hexacyanoferrate nanocubes with manganese oxide nanosheets for high performance rechargeable zinc ion batteries. J. Mater. Chem. A 5, 23628-23633 (2017). https://doi. org/10.1039/C7TA07834J

53. K. Lu, B. Song, J. Zhang, H. Ma, A rechargeable Na-Zn hybrid aqueous battery fabricated with nickel hexacyanoferrate and nanostructured zinc. J. Power Source 321, 257-263 (2016). https://doi.org/10.1016/j.jpowsour.2016.05.003 